\title{
ACT, INTENTION, AND MOTIVE IN THE CRIMINAL LAW
}

In the Return of Sherlock Holmes we are told of an "attempt to murder Mr. Sherlock Holmes" under the following circumstances. Holmes expected that an attempt on his life would be made by Colonel Moran. He therefore prepared a wax figure of himself. This he put in a life-like position in the armchair in his room. The window-shade was pulled down and a strong light placed so as to throw the silhouette of the figure onto the shade. The more completely to carry out the deception, Holmes arranged with his landlady to move the figure from time to time so as to give it an appearance of life, of course keeping herself concealed and out of range of possible bullets. Thus arranged, the figure offered a tempting target. Holmes and the faithful Watson concealed themselves in an empty house across the street and patiently awaited developments. As luck would have it, Colonel Moran chose the same house and room as the place from which to attack Holmes, and fired from a window of the house. The bullet struck the wax figure in the forehead. The Colonel was immediately seized and placed under arrest. The police proposed to prosecute him for "the attempted murder of Mr. Sherlock Holmes." Unfortunately for us the culprit was held for the previous murder of another person and was never brought to trial upon the charge of attempt to murder. If this charge had been pressed, upon proof of the facts stated above, could the accused have been convicted of a criminal attempt to murder Holmes? Would it have been different if the windowshade had been up and the figure itself, instead of the silhouette, had been visible to the Colonel? That there should be any doubt that in both cases Colonel Moran was guilty of a criminal attempt to murder Holmes would probably surprise a layman, but a consideration of the authorities upon attempts-or at least of the opinions of some of the judges and legal authors who have written upon the question-tends to throw doubt upon the matter. Indeed, if we apply tests which have occasionally been suggested it would seem that in the first case the accused was guilty, but that in the second case he was not guilty, of a criminal attempt to murder: ${ }^{1}$

\footnotetext{
${ }^{1}$ See the opinion by Bartlett, J., in People v. Jaffe (1906) 185 N. Y. 497 and the discussion of Criminal Attempts by Professor Joseph $\mathrm{H}$. Beale in (Ig03) I6 HARV. L. REv. 49I.
} 
In view of this confusion as to the tests by which we are to determine whether or not a criminal attempt has been committed-a confusion which exists to some extent in the actual decisions but to a greater extent, it is believed, in the opinions of judges and the writings of legal authors-it is proposed to examine anew the whole question. In undertaking to do this the present writer does not cherish the illusion that a simple solution of this difficult problem can be found. It is, however, hoped that an attempt at an analysis somewhat more careful than that usually given will throw additional light upon the real problems involved. Fully to accomplish the purpose in view will require a preliminary discussion of a few of the more common terms used in criminal law, as well as of the actual concepts which underlie them. This will be undertaken in the present article. A second article will be devoted to an analysis of criminal attempts.

It is a common saying that every crime may be looked at as composed of two elements: (I) an act and (2) the intention, or state of mind with which the act is done. ${ }^{2}$ In connection with the latter the question most commonly asked is, "Did or did not the one who did the act intend to bring about the results which actually took place? Was that his intention?" However simple and clear such statements and questions may appear to be at first sight, a moment's reflection reveals that the two terms, act and intention, are by no means free from ambiguity. One writer or judge will use them in one sense, another in a different sense; indeed, the same writer will not always be consistent in his usage. We must, therefore, begin by noting the various possible meanings which each of these terms may have-meanings more or less sanctioned by current modes of expression in the legal world. When this has been done, we may perhaps be

\footnotetext{
2 "The intent and the act must concur to constitute the crime." Per Lord Kenyon, C. J., in Fowler v. Padget (I798) 7 T. T. a, 514. "To constitute a crime, there must, as a rule, be both a guilty mind and a criminal act." Odgers, The Common Law of England, p. 106. "Every common law crime consists of two elements: first, the voluntary commission of an act which is declared by the law to be criminal; second, the existence in the offender of a state of mind which is declared by law to be consistent with criminality." May, Criminal Law (3d ed.) sec. 5. Sometimes intent is used; at other times, intention. Throughout the present discussion the latter has been used. Both of these of course in many cases are used as meaning merely state of mind, as for example, in the question, "What was his intention?"
} 
in a position to give to each of these words some one particular meaning which will be the most useful for the purposes of the present discussion.

First then of the term act: no word is more commonly used by judges and writers upon law, as a rule apparently without much thought of any possible ambiguity. Legal literature is full of phrases such as "the criminal act," "an act of homicide," "an act of trespass," etc., etc. Let us analyze one of these phrases. Take, for example, "an act of homicide." Suppose A murders B by shooting him with a pistol. What is "the act?" The usual answer would probably be, "the act of killing B." Even a brief consideration shows us that we have here a complex rather than a simple thing; that if we are to use words in an accurate, scientific manner we must recognize that the term act is here used so as to include more than one thing. Apparently it covers ( $I$ ) what may be called the act (or series of acts) in a narrow sense of the word, i. e., a muscular movement (or movements) willed by the actor; (2) some reference to the surrounding circumstances; (3) the consequences or results of the movement (or movements). It seems obvious that if we are to make any careful analysis, we must distinguish between these three things; to do so, we need to have separate names for them. Perhaps we cannot do better than to restrict the word act to the narrower sense above suggested, i. e., so that it means simply a muscular movement that is willed. If we do this, we can say that in considering criminal liability we have to consider (I) the act (or acts); (2) the concomitant circumstances; (3) the consequences; (4) the actor's state of mind at the time he acts with reference to these circumstances and consequences. In the concrete case which we are considering, in this narrower sense of the word the acts of $A$ consist of a series of muscular movements willed by $A$. The concomitant circumstances include, for example, the fact that $B$ was within range of the pistol; that the pistol was loaded, etc., etc. The consequences of A's acts are of course very numerous; some are, for example, the pistol is raised and turned in B's direction; the trigger is pulled back; the hammer falls; the powder is ignited and explodes; the bullet is expelled from the pistol, goes through the air toward $B$, strikes the surface of B's body and penetrates the same; as a result B's body undergoes physical changes which result in death. Strictly and scientifically, all these things and many others are not parts of A's act but merely the consequences of the same. This use of the 
term act in this narrow sense is sanctioned by many of the most eminent writers on jurisprudence. For example, Austin says:

"Most of the names which seem to be names of acts, are names of acts, coupled with certain of their consequences. For example, If I kill you with a gun or pistol, I shoot you: And the long train of incidents which are denoted by that brief expression, are considered (or spoken of) as if they constituted an act, perpetrated by me. In truth, the only parts of the train which are my act or acts, are the muscular motions by which I raise the weapon; point it at your head or body, and pull the trigger. These I will. The contact of the flint and steel; the ignition of the powder, the flight of the ball towards your body, the wound and subsequent death, with the numberless incidents included in these, are consequences of the act which I will. I zeill not those consequences, although I may intend them."s

Mr. Justice Markby takes the same view: He says:

"I will analyse a little further the nature of an act. An act is the bodily movement which follows immediately upon a volition. What follows upon an act in connection with it are its consequences. It is necessary to remember this, although, in common language, we often use the word 'act' to express both an act and its consequences; as, for example, when we speak of an act of murder. Without a bodily movement no act can be done. A silent and motionless man can only forbear."4

Mr. Justice Oliver Wendell Holmes expresses his agreement with this view in the following characteristically terse passage:

"An act is always a voluntary muscular contraction, and nothing else. The chain of physical sequences which it sets in motion or directs to the plaintiff's harm is no part of it, and very generally a long train of such sequences intervenes."

Often, however, as some of the phrases quoted above show, the term act is used more loosely, and may be regarded as a more or less convenient shorthand expression to describe not

${ }^{3}$ Jurisprudence (5th ed.) p. 415 .

Elements of Law (6th ed.) sec. 215.

'The Common Law, p. 91; cf. Stephan, General View of the Criminal Law of England (2d ed.) pp. 68-69. 
only the act in this narrow sense but also some portion of the accompanying circumstances as well as of the consequences. For example, Mr. Solicitor General Salmond says:

"The term act is one of ambiguous import, being used in various senses of different degrees of generality. When it is said, however, that an act is one of the essential conditions of liability, we use the term in the widest sense of which it is capable. We mean by it any event which is subject to the control of the human will. Such a definition is, indeed, not ultimate, but it is sufficient for the purpose of the law. As to the nature of the will and of the control exercised by it, it is not for lawyers to dispute, this being a problem of psychology or physiology, not of jurisprudence. . . .

By some writers the term act is limited to that part of the act which we have distinguished as its origin. According to this opinion the only acts, properly so called, are movements of the body. 'An act,' it has been said, 'is always a voluntary muscular contraction and nothing else.' That is to say, the circumstances and consequences of an act are not part of it, but are wholly external to it. This limitation, however, seems no less inadmissible in law than contrary to the common usage of speech. We habitually and rightly include all material and relevant circumstances and consequences under the name of the act. The act of the murderer is the shooting or poisoning of his victim, not merely the muscular contractions by which this result is effected. To trespass on another man's land is a wrongful act; but the act includes the circumstance that the land belongs to another man, no less than the bodily movements by which the trespasser enters upon it."”

It is believed by the present writer that in a careful analysis of legal responsibility the less wide meaning given to act by the writers first quoted is preferable to this looser usage. The suggestion of Salmond that so to limit the word is to run counter to accepted usage seems incorrect, except in so far as that is

\footnotetext{
- Salmond, Jurisprudence (4th ed.) pp. 323, 326. This loose use of the word act is of course common in judicial opinions as well as in popular language. "Where a man stands on the New York side of the [State] line, and shooting across the border, kills one in New Jersey ... the blow is in fact struck in New Jersey. It is the defendant's act in this state [New Jersey]. The passage of the ball, after it crosses the boundary, and its actual striking, is the continuous act of the defendant." Vrendenburgh, J., in State v. Carter (1859) 3 Dutch. (N. J. L.) 499. Cf. the opinion of Garoutte, J., in People v. Botkin (Igor) I32 Cal. 23x.
} 
involved in all attempts to limit to one meaning a word which in popular speech has more than one.

The difficulties irrvolved in the broader use of the term are shown by the following passage from Salmond which follows immediately that quoted above:

"It may be suggested that although an act must be taken to include some of its consequences, it does not include all of them, but only those which are direct or immediate. Any such distinction, however, between direct and indirect, proximate and remote consequences, is nothing more than an indeterminate difference of degree, and cannot be made the basis of any logical definition. The distinction between an act and its consequences, between doing a thing and causing a thing, is a merely verbal one; it is a matter of convenience of speech, and not the product of any scientific analysis of the conception involved. There is no logical distinction between the act of killing a man and the act of doing something which results (however remotely) in his death."

This leads us into this difficulty: the death of the victim is not the last consequence of the act; an infinite series of more remote consequences follows. As a farther result, for example, the victim's family was starved to death because of non-support, etc., etc. Are all these "logically" parts of "the act" as thus defined? Is it really intended to include under act all the consequences, however remote, of a voluntary muscular movement? If so, all that can be said is that even popular language does not go so far, and there seems to be no utility in so extending the meaning of the word. Indeed, the difficulties into which we fall if we use act in this wider sense could not be more clearly illustrated than by the passage just quoted. "The distinction between an act and its consequences . . . . . is a merely verbal one," says the learned author, adding in explanation: "There is no logical distinction between the act of killing $a$ man and the act of doing something which results (however remotely) in his death."8 This is quite true if we use act to include consequences, but not if we use it in the narrow and more accurate sense of a muscular movement that is willed. The distinction between that and its consequences in the outer world is not "merely verbal" but a very important one in fact. ${ }^{\circ}$

\footnotetext{
'Salmond, Jurisprudence (4th ed.) pp. 326, 327.

8 The italics are those of the present writer.

- It seems that the learned writer has used act in two senses in the passage quoted. If the "consequences" are part of the "act," they
} 
To be sure, when no strict and accurate analysis is involved there is perhaps no very serious objection to the rather loose usage current among both laymen and lawyers, and it has a certain convenience as a shorthand method of expression. The moment, however, that we leave the field of loose discussion and enter that of careful analysis, we need terms that express distinctions which clearly do exist and must be taken account of. For this reason in the present discussion the term act will be used, unless otherwise indicated, to signify a muscular movement that is willed.

The broader meaning given to the word act by Mr. Salmond is to be distinguished from the somewhat unusual one found in the following passages taken from Professor Beale's discussions of "Recoverry for the Consequences of an Act," and of "Criminal Attempts."

"In all cases of personal injury or direct injury to property, the act is the physical contact between the person or property injured and the outside force. It is immaterial which element of the combination is the active one. My act is the same, whether I thrust a sharp stick into A, or fix the stick, and cause $A$ to run upon it; whether I pour water over him, or cause him to jump into a river; whether I pack him in ice and salt, or cause him to be exposed to the freezing air; whether I throw him upon a pile of bricks, or by removing a staging cause a load of bricks to fall upon him. My act in these cases is not fastening the stick, inducing the man to jump, turning him out of doors, or removing the staging; it is bringing into contact with the man's body the stick, water, cold air, and bricks respectively. If I so negligently manage a vessel of which I am master as to run down and sink another vessel and drown a passenger in it, my act of injury is not the mismanagement of my vessel, but the fatal contact between the passenger and the ocean. My negligence is important only in determining whether I am responsible for that contact." .....

"The defendant's act, in the first instance, consisted in setting some force in motion; and we are to hold him

are not consequences of it ("the act"): The learned author recognizes this when he says: "It is unfortunate that there is no recognized name for the origin or initial stage of act, as contrasted with the totality of it. Bentham calls the former the act and the latter the action. Principles, ch. 8 , sect. 2. Works, I. p. 40 . But in common usage these two terms are synonymous, and to use them in this special sense would only lead to confusion." P. 326 , note 2 . 
responsible for the act of injury on the ground that this force is a factor of the act. . . . . ${ }^{10}$

"An attempt may be described as an act regarded as a step toward another act. . . . . . .

In investigating criminal attempt, therefore, we are to consider, first, what was the intended result which is regarded by the law as a criminal act; and secondly, what has the defendant done as a step toward bringing about that result. . . . .

The point in the chain of results selected by the law as the criminal act is the contact of the poison with the tissues of the body. The physical harm, not the death of the victim, is the criminal act; the death, being subsequent, is, as we have seen, an immaterial factor in considering the attempt to commit the crime.

It is quite true that in the ordinary use of language a man attempts to bring about results as well as to do acts; that when a murderer in intention fires a pistol he is attempting not only to put a bullet into the object aimed at, but to cause the death of his intended victim, who may be a hundred miles away. But attempt in that sense, having a mere mental connection with the intended result, is not the concern of the criminal laze, which punishes physical acts only."11

Apparently act is here used, although not consistently, as including merely one of the consequences of the muscular movement of the actor, exclusive of the real act (muscular movement) itself. It is difficult to see why we should single out this particular physical consequence of the act (muscular movement that is willed) and call it "the act," and treat the consequences which follow as "consequences" of the (so-called) "act."

A few words must of course be said in explanation of what is meant by saying that the muscular movement in order to be called an act must be willed. For our purposes the analysis presented in many of the standard treatises on jurisprudence seems entirely sufficient, without any attempt to go into the more philosophical aspects of the subject. Austin may be taken as an example. He says:

"Certain parts of the human body obey the zeill. Changing the expression, certain parts of our bodies move

\footnotetext{
${ }^{10}$ Recovery for Consequences of an Act (1896) 9 HARv. L. REv. 82, 84 The italics are those of the present writer.

${ }^{12}$ Criminal Attempts (r903) I6 HARV. L. REv. 492, 493. The italics are those of the present writer.
} 
in certain ways as soon as we will that they should. Or, changing the expression again, we have the power of moving, in certain ways, certain parts of our bodies.

Now these expressions, and others of the same import, merely signify this:

Certain movements of our bodies follow invariably and immediately our wishes or desires for those same movements: Provided, that is, that the bodily organ be sane, and the desired movement be not prevented by an outward obstacle or hindrance. If my arm be free from disease, and from chains or other hindrances, my arm rises, as soon as I wish that it should. But if my arm be palsied, or fastened down to my side, my arm will not move, although I desire to move it. . . . . .

All that I am able to discover when I will a movement of my body, amounts to this: I wish the movement. The movement immediately follows my wish of the movement. And when I conceive the wish, I expect that the movement wished will immediately follow it. Any one may convince himself that this is the whole of the case, by carefully observing what passes in himself, when he zeills to move any of the bodily organs which are said to obey the will, or the power or faculty of willing."12

On the same point Holland says:

"Any discussion on the nature of the faculty of will and the mode of its exercise would here be out of place. We may accept as sufficient for our purpose the definition of an act of will as 'the psychical cause by which the motor nerves are immediately stimulated,' or as, 'that inward state which, as experience informs us, is always succeeded by motion while the body is in its normal condition,' e. $g$. is not paralysed.

If a movement is caused by physical compulsion, 'vis absoluta,' as when the hand of a person is forcibly guided in making a signature, there is no act, since will is absent.

But the will itself, being amenable to motives, may be coerced by threats, 'metus,' 'vis compulsiva,' 'duress per minas.' Here there is indeed an act but one which produces none or few of the legal consequences which it would have produced had it been the result of free volition."13

Keeping in mind that in our discussion we are to distinguish sharply between the act properly so-called, its concomitant cir-

${ }^{12}$ Jurisprudence (5th ed.) Vol. I, 4rr-412.

${ }^{23}$ Jurisprudence (roth ed.) p. 103. 
cumstances, and the resulting consequences, we must now examine these other elements more carefully. In order to determine the criminal responsibility of the actor, we must determine what his state of mind with reference to these other elements was. The most important problem in criminal law in this connection is whether the actor did or did not intend certain consequences to follow from his act or acts. ${ }^{14}$ Was it his intention to produce them? At once we are confronted by the usual dilemma, viz., that it is not clear without discussion just what these muchused words intend and intention mean. Do they, for example, mean simply that when he acted the actor wished or desired these consequences to follow and so did the act in order that they might so follow? Some writers seem to think so; for example, Mr. Justice Markby says:

"Intention, then, is the attitude of mind in which the doer of an act adverts to a consequence of the act and desires it to follow. But the doer of an act may advert to a consequence and yet not desire it: and therefore not intend it."15

At first thought one is inclined to agree with this, but once again a little reflection tends to throw doubt upon the matter. The problem may perhaps best be treated by the consideration of concrete cases. (I) Suppose, as one case, that B is standing near a target at which $\mathrm{A}$ wishes to shoot. A realizes that if he attempts to hit the target he will be about as likely to hit B as to hit the target: nevertheless he fires, wishing to hit the target, but hoping, indeed, that he will not hit $B$. If $B$ is hit, shall we say that $A$ intended to hit $B$., $i$. e., that that consequence which actually did follow A's act was intended by him? Was it his intention to produce that consequence? Mr. Justice Markby of course would say "No"; Austin with equal promptness would say "Yes." He says:

"You shoot at Sempronius or Styles, at Titius or Nokes, desiring and intending to kill him. The death of Styles

\footnotetext{
14 A complete discussion of criminal liability would require of course a discussion of consequences not intended, and of what is meant by negligence, heedlessness, rashness, etc. For a discussion of criminal attempts, however, it will be sufficient to obtain an accurate notion of what we mean when we say that the actor intended certain consequences to follow from his act.

${ }^{25}$ Markby, Elements of Law (6th ed.) sec. 220.
} 
is the end of your volition and act. Your desire of his death, is the ultimate motive to the volition. You contemplate his death, as the probable consequence of the act.

But when you shoot at Styles, I am talking with him, and am standing close by him. And from the position in which I stand with regard to the person you aim at, you think it not unlikely that you may kill $m e$ in your attempt to kill him. You fire, and kill me accordingly. Now here you intend my death, without desiring it. The end of the volition and act, is the death of Styles. $M y$ death is neither desired as an $e n d$, nor is it desired as a mean: $M y$ death subserves not your end: you are not a bit nearer to the death of Styles, by killing me. But, since you contemplate my death as a probable consequence of your act, you intend my death although you desire it not."18

Bentham apparently took the same view, if we may judge from the following passage:

"A consequence, when it is intentional, may either be directly so, or only obliquely. It may be said to be directly or lineally intentional, when the prospect of producing it constituted one of the links in the chain of causes by which the person was determined to do the act. It may be said to be obliquely or collaterally intentional, when, although the consequence was in contemplation, and appeared likely to ensue in case of the act's being performed, yet the prospect of producing such consequence did not constitute a link in the aforesaid chain. . . He [the actor] saw a stag running that way, and he saw the king riding that way at the same time: what he aimed at was to kill the stag: he did not wish to kill the king: at the same time he saw, that if he shot, it was as likely he should kill the king as the stag: yet for all that he shot, and killed the king accordingly. In this case the accident of his killing the king was intentional, but obliquely so."17

We thus find that usage is divided. Before making a choice between the meanings suggested by the writers quoted, let us note that other writers apparently have given a still different significance to these words. (2) Take for example, as a second case, the following state of facts: $\mathrm{X}$ wishes to kill $\mathrm{A}$ by blowing him to pieces through exploding a stick of dynamite. $B$ is standing so near $A$ that he also will necessarily, not merely

\footnotetext{
${ }^{16}$ Austin, Jurisprudence (5th ed.) Vol. I, p. 424.

${ }^{17}$ Bentham, Principles of Morals and Legislation, chap. viii.
} 
probably, be killed by the explosion. $X$, although he has no ill-will toward $B$, and would be glad to spare him, nevertheless explodes the dynamite in order to destroy A. Assuming that $\mathrm{X}$ knew that the result necessarily would be the death of $\mathrm{B}$ as well as of $A$, shall we say, when that result follows, that $X$ intended it? Did he intend to kill $B$ as well as $A$ ? If so, can we also truthfully say that $\mathrm{X}$ wished or desired $\mathrm{B}$ 's death, or merely that, while he intended it, he did not wish or desire it? Before giving a final answer to these questions let us consider still another hypothetical case which will perhaps serve to reveal more fully the shades of meaning which may be attached to the word intend. (3) Suppose $\mathrm{X}$ wishes to kill $\mathrm{A}$ with a rifle bullet. $B$ is standing between $X$ and $A$, so that the bullet from $X$ 's rifle, if it is to reach A, must necessarily pass through B's body. In spite of this, $X$ aims and fires, and the bullet, pursuing the course $\mathrm{X}$ wishes, passes through B's body before it strikes $\mathrm{A}$. Here clearly all would agree that $\mathrm{X}$ intended the bullet to go through B's body, for only by having it do so could the purpose for which he fired be accomplished. To be sure, he intended this consequence to $B$ only as a means to an end and not as an end in itself, but that does not alter the fact that he actually intended that it should happen. ${ }^{18}$

As already stated, our problem is chiefly one of choosing a convenient terminology, i. e., one which will, on the whole, be of the greatest aid to clear thinking and accurate analysis, and at the same time be most nearly in accord with current usage, so far at least as the latter is possible consistently with the former. For reasons which will perhaps reveal themselves as the

\footnotetext{
28 "I endeavour to explain what I mean, when I say, "that a consequence of an act may be wished as an end.' Strictly speaking, no external consequence of any act is desired as an end. The end or ultimate purpose of every volition and act is a feeling or sentiment:-is pleasure, direct or positive; or is the pleasure which arises indirectly from the removal or prevention of pain. But where the pleasure, which (in strictness) is the end of the act, can only be attained through a given external consequence, that external consequence is inseparable from the end; and is styled (with sufficient precision) the end of the act and the volition. For example, if you shoot me to death because you hate me mortally, my death is a necessary condition to the attainment of your end. The end of the act, is to allay the deadly antipathy. But the end can only be attained through my death. And my death (which is an intended consequence of the act) may, therefore, be styled the end of the act and the volition." Austin, Jurisprudence (5th ed.) Vol. I, p. 422.
} 
discussion proceeds, it seems to the present writer desirable to restrict the scope of the word intend more narrowly than does Austin, but not quite so narrowly as does Markby. In doing so we shall in substance follow Mr. Salmond's definition of these terms. He says:
"Although nothing can be intended which is not desired, it must be carefully noticed that a thing may be desired, and therefore intended, not in itself or for its own sake, but for the sake of something else with which it is neces- sarily connected. If I desire and intend a certain end, I also desire and intend the means by which this end is to be obtained, even though in themselves those means may be indifferent, or even objects of aversion. If I kill a man in order to rob him, I desire and intend his death, even though I deeply regret, in his interests or in my own, the necessity of it. In the same way, the desire and intention of an end extend not merely to the means by which it is obtained, but to all necessary concomitants without which it cannot be obtained. If an anarchist, desiring to kill the emperor, throws a bomb into his carriage, knowing that if it explodes and kills him it will also kill others who are riding with him, the assassin both desires and intends to kill those others: This additional slaughter may in itself be in no way desired by him; he may be genuinely sorry for it; yet it falls within the boundaries of his desire and of his intent, since it is believed by him to be a necessary concomitant of the end which he primarily seeks. The deaths of the emperor and of the members of his suite are inseparably connected, and they constitute, therefore, a single issue which must be desired and intended as a unity or not at all. When I know or believe that A. cannot be had without B., I cannot say that I intend $A$. but not $B$. If I desire $A$. sufficiently to over- come my aversion to $B$., then I desire the total issue of which $A$. and $B$. are the two inseparable factors. With respect to all circumstances which I know or believe to exist, and with respect to all consequences which I know or believe to be inevitable, my act is intentional, however undesirable those circumstances or consequences may be in themselves. I choose them deliberately and consciously as necessary incidents of that which I desire and intend for its own sake."19

In accordance with this, we shall say that an actor intends a particular consequence when either (I) he wishes or desires it to happen as the result of the act which he does for the purpose of

\footnotetext{
${ }^{10}$ Salmond, Jurisprudence (4th ed.) p. 337.
} 
bringing about the result in question; or (2) when at the time he does the act he adverts to the consequence in question as one which will necessarily result from the act, and this even if he would be glad to have this particular consequence not happen if he could avoid it and still bring about the consequence which he has primarily in view. Using intend in this sense, our three hypothetical cases may now be answered as follows. In the first-where the consequence was adverted to as probable but not as necessary-the actor neither desired nor intended the consequence; he merely expected it, or had knowledge that it would be likely to happen if he did the act. Mere expectation, or knowledge by the actor that a given consequence will be likely to happen as a result of his act is not the same as an intention that it shall happen. In the second case-where he adverted to the consequence as necessary and not merely as probable, but would have been glad to avoid it if he could, and yet accomplish his chief purpose-he intended the consequence although (it seems) he did not really desire it. In the third case-that in which the bullet had to go through B's body in order to strike A-clearly the actor intended the consequence in question, and perhaps-although that is more doubtful-desired it as well.

In making this choice in favor of a meaning narrower than that given to this term by many writers, it is realized that the wider meaning is not without its utility and to some extent more in keeping with the habits of speech of many common-law judges and writers. The common statement that a person is "presumed by the law to intend the natural and probable consequence of his acts" seems, at least in some cases, to be a somewhat loose way of stating Austin's definition of intent. On the whole, however, it is believed that the balance of convenience is against the wider use of the term, as the narrower use here advocated compels us to discriminate more carefully between states of mind that in fact are different, and involve different legal consequences in many cases.

Another word in common use in discussions of criminal law is motive. Frequently it is contrasted with intention. For example, Mr. Justice Stephen says:

"It is important to distinguish between motives and intentions. An intention to do anything is consistent with any number of different motives, and may remain unchanged while the motives vary. In the crime of pub- 
lishing a libel the intention must always be to give more or less publicity to a certain libel. The motives for this may be infinite, and may vary from time to time. So an intention to kill may be the result of all sorts of motives. It may be the act of an executioner, of a soldier in time of war, of a man defending his own life, of a murderer. The intent to kill is the same in all these and many other cases. Intention is a much more definite thing than motive, and is usually of much greater importance in criminal cases." 20

To what extent is this distinction between motive and intention as made by the learned author a sound one? Is the difference fundamental or is motive merely a name for a certain kind of intention? The latter seems to be the view of the author of the following passage:

"A wrongful act is seldom intended and desired for its own sake. The wrongdoer has in view some ulterior object which he desires to obtain by means of it. The evil which he does to another, he does and desires only for the sake of some resulting good which he will obtain for himself. He intends the attainment of this ulterior object, no less than he intends the wrongful act itself. His intent, therefore, is twofold, and is divisible into two distinct portions, which we may distinguish as his immediate and his ulterior intent. The former is that which relates to the wrongful act itself; the latter is that which passes beyond the wrongful act, and relates to the object or series of objects for the sake of which the act is done. The immediate intent of the thief is to appropriate another person's money, while his ulterior intent may be to buy food with it or to pay a debt. The ulterior intent is called the motive of the act.

The immediate intent is that part of the total intent which is coincident with the wrongful act itself; the ulterior intent or motive is that part of the total intent which lies outside the boundaries of the wrongful act. For just as the act is not necessarily confined within the limits of the intent, so the intent is not necessarily confined within the limits of the act. The wrongdoer's immediate intent, if he has one, is his purpose to commit the wrong; his ulterior intent, or motive is his purpose in committing it. Every wrongful act may raise two distinct questions with respect to the intent of the doer. The first of these is: How did he do the act-Intentionally or accidentally? The second is: If he did it intentionally,

${ }^{\infty}$ Stephen, General View of the Criminal Law of England, p. 71. 
why did he do it? The first is an inquiry into his immediate intent; the second is concerned with his ulterior intent, or motive."21

Perhaps the matter may be stated somewhat as follows. Nearly all consequences which are intended and desired by the one whose act produces them are not desired for their own sake. The actor has in view some farther, more remote consequence or consequences which he is seeking to bring to pass by means of these less remote, more immediate consequences. If, for example, he deliberately inflicts injury upon another, he does so not because he desires this injury as an end in itself, but for the sake of some resulting good which he expects to obtain for himself. Inasmuch as he desires this more remote consequence to occur as a result of his act, he intends it no less than he does the more immediate consequences. His intention as well as his desire therefore covers many consequences, some of which he desires and intends as means for producing still farther consequences, others as ends in themselves. When $A$ for the purpose of killing $B$ intentionally produces the consequence that a rifle bullet strikes B's body, he both desires and intends not only that consequence but also many others, including the death of $B$. If he is killing for revenge, he desires and intends all the foregoing consequences as means to bring about the feeling of pleasure which he expects to derive from B's death. He desires and intends this feeling of pleasure to result from his act just as much as he desires and intends the other consequences so to result. The desire and intention to bring about this ulterior consequence which is the end, rather than merely a means to an end, seem to be what is meant in many cases by motive. In the case put, it would probably be said by many that A's intention was to kill $\mathrm{B}$, but that his motive for so intending was to experience the pleasurable feeling which he expected would result from the death of $B$. If $A$ 's object in killing $B$ had been to obtain B's money, it would be said that his intention was to kill $\mathrm{B}$, and that his motive was to obtain the money. In this sense, therefore, motive seems to be merely a name for the desire coupled with the intention to bring about a certain consequence

\footnotetext{
${ }^{21}$ Salmond, Jurisprudence (4th ed.) pp. 338-339. The learned reader will note that in this passage the word act is used by the learned author with the broader meaning which he prefers to give to it.
} 
as an end, ${ }^{22}$ by means of other consequences which are also desired and intended but only as means. ${ }^{23}$

Inasmuch as-according to the definition of those terms which we have adopted-a consequence miay be intended although perhaps not, strictly speaking, desired, it seems inaccurate to speak of motive as being the ulterior intention merely, without coupling with it the desire as well. That is, if the intention is simply to produce a consequence not desired but merely contemplated as one that will necessarily result from the act and certain of its consequences, obviously an intention of this kind can not be called the motive with which the act is done and the earlier consequences produced. The important element clearly is the desire, and not merely the intention, to produce the ulterior consequence.

If motive is merely a name for a certain kind of desire and intention, can we accept without qualification the statement of Mr. Justice Stephen above quoted, to the effect that "intention is usually of much greater importance than motive in criminal law ?" May it not turn out to be true that in many cases whether a crime has been committed will depend upon the motive with which the acts that have produced certain results were done? For example, intentional homicide may be either lawful or unlawful. If one kills merely for revenge or in order to obtain property, the crime of murder is committed; if, on the other hand the killing is done in the due execution of a sentence of death upon a convicted criminal, or, under proper circumstances, for the prevention of felony or in defense of oneself, the homicide is lawful. Can we say in these cases that the lawfulness or unlawfulness depends upon the motive, i. e., the desire and intention-

" "End" is here used as including both the internal consequence which is, strictly speaking, the end, and the external consequence without which the internal could not be obtained. Compare note 18 , supra.

${ }^{2}$ Frequently of course motive is used as the name for the external object desired, rather than for the desire itself. Cf. Bentham, op. cit. chap. $X$. It seems also that, at least occasionally, the desire and intention to produce an ulterior consequence which is not the ultimate consequence sought is called the motive with which a prior consequence was produced. For example, it may be said that my motive in pulling the trigger of a rifle is the desire and intention to cause the powder to explode, or the bullet to leave the barrel of the rifle. At times also purpose is used apparently as a synonym for motive. In the passage quoted above from Mr. Salmond, it is said: "His ulterior intent, or motive is his purpose in committing it" 
for example, to prevent a felony or to defend oneself? If so, it would follow that although there may exist all the external circumstances which would justify one in killing to prevent felony or in self-defense, he would still be guilty of murder, if he should kill solely for revenge and not with the motive (desire and intention) to save his life or to stop the commission of the felony. It would of course be difficult, if not impossible, to prove that revenge was the motive in such a case, and it is not surprising therefore that authorities expressly passing upon the question are difficult to find. Many dicta, however, if not decisions, indicate that this is the true view of the law. ${ }^{24}$ It is also implied in the usual statements of the rule governing these situations. For example, in his Digest of the Criminal Law Mr. Justice Stephen states these rules as follows:

"The intentional infliction of death or bodily harm is not a crime when it is done by any person in order to prevent the commission of treason, murder, etc., . . . [or] when it is inflicted by any person in order to defend himself, etc." ${ }^{\prime 25}$

As previously stated, the foregoing discussion is intended not as a complete analysis for the whole field of criminal law, but merely as a foundation for the discussion of criminal attempts which will be undertaken in a second article. At many points it has therefore intentionally been left incomplete. For example, the discussion of the various meanings of intend and intention deals only with the simpler aspects of the problem and does not raisse the most difficult questions which demand solution in a study of criminal attempts. This is due to the fact that it was assumed that exactly the consequences desired and intended by the actor were actually caused by the act. The word attempt

\footnotetext{
"People v. Willians ( 1867 ) 32 Cal. 280; Wortham v. Georgia (1883) $70 \mathrm{Ga} .336$; Lyons $v$. The State (189r) I37 Ill. 602. The following passage from the opinion of Lumpkin, J., in Golden $v$. The State (1858) 25 Ga. 527, is apparently contra: "Whenever the circumstances of the-killing would not amount to murder, the proof even of express malice will not make it so. One may harbor the most intense hatred toward another; he may court an opportunity to take his life; may rejoice while he is imbruing his hands in his heart's blood; and yet, if, to save his own life, the facts showed that he was fully justified in slaying his adversary, his malice shall not be taken into the account. This principle is too plain to need amplification."
}

* (6th ed.), Articles 220, 22I. The italics are those of the present writer. 
itself, however, indicates that for some reason or other all the consequences desired and intended were not produced, or, as it is commonly put, that the "completed crime was not committed." In the belief that this phase of the matter can be most conveniently treated in dealing with concrete cases of alleged attempts, a complete analysis has not been attempted in this general preliminary survey, but will be undertaken later in the second and more concrete part of the discussion.

\section{WALter WheELer CoOK.}

Yale UnIVERSity, School of LAW. 